\title{
Registered nurses' perceptions of the discharge planning process for adult patients in an acute hospital
}

\author{
Jenny Morris, Louise Winfield, Kim Young \\ Faculty of Health, Plymouth University, Truro, England \\ Correspondence: Jenny Morris, Address: Faculty of Health, Education \& Society, Plymouth University, Knowledge Spa, \\ Treliske, Truro, England TR1 3HD. Telephone: 01872 256461. E-mail: jenny.morris@plymouth.ac.uk
}

Received: October 8, 2011

DOI : $10.5430 /$ jnep.v2n1p28
Accepted: November 28, $2011 \quad$ Published: February 1, 2012

URL: http://dx.doi.org/10.5430/jnep.v2n1p28

\section{Abstract}

Background: Discharge planning is an integral part of the care undertaken by registered nurses, and yet there is research that demonstrates a lack of coherence and consistency in how registered nurses perceive discharge planning. In England, this is of national concern as discharge planning was one of 10 themes identified by the Healthcare Commission in the context of patient complaints. The aim of this study was to explore perceptions around the discharge planning process of registered nurses working in an acute hospital.

Methods: Cross-sectional, postal survey of 461 registered nurses working in clinical areas where patients were normally discharged home. Data were collected using a discharge planning questionnaire modified for the purpose of this study.

Results: $76 \%$ of nurses agreed that discharge planning was the responsibility of the patient's allocated nurse and $79 \%$ agreed that planning should be commenced on admission to the unit. $76 \%$ agreed that an estimated discharge date was provided for each patient, but only $37 \%$ agreed that this was always communicated to patients, and $25 \%$ disagreed that patients were fully involved in the discharge planning process. $21 \%$ agreed that nurses in general lacked understanding of the discharge process. The key roles of nurses were considered to be liaison, assessment and patient advocacy, and requisite skills focused on management and personal skills. The main barriers to discharge planning centred on poor planning and communication, inadequate staffing levels, and poor liaison with external agencies.

Conclusions: The findings indicate that despite policy changes there are identifiable issues that if addressed could improve the discharge planning process. Most hospital patients need discharging and so it is vital that rigorous systems and processes are adopted to ensure an efficient and timely discharge.

\section{Key words}

Discharge planning, Simple discharge, Acute care, Registered nurses, Survey

\section{Introduction}

In England it has been estimated that $80 \%$ of discharges are classified as simple, defined as patients who will usually be discharged to their own home, and/or have simple ongoing care needs ${ }^{[1]}$. All registered nurses should be competent to co-ordinate discharge planning for this group of patients. The importance of effective and efficient discharge planning 
procedures has been highlighted in several government reports as a means by which unnecessary lengths of stay can be avoided, patient satisfaction increased, and more cost-effective care provided ${ }^{[2]}$. However, as yet there is a lack of robust and convincing evidence to suggest that these outcomes are achieved ${ }^{[3,4]}$. In 2007 the Healthcare Commission in England reported that of 16,000 complaints received between July 2004 and July 2006, 5\% related to 'discharge from hospital and service co-ordination' which was one of ten common themes identified. Some complaints were about the lack of notice given to families before discharge of a relative from hospital; others involved the discharge of vulnerable patients (including children and the elderly) without any support or at inappropriate times of the day ${ }^{[5]}$. In summarising the key issues to emerge from recent policy documents, it was emphasised that discharge planning should commence at pre-admission clinic or on admission to hospital ${ }^{[6]}$. In order for any policy to succeed, it is essential to understand the context in which policy is applied; as well as the attitudes and perceptions of those involved with implementation. Whilst it has been stated in policy documentation that all registered nurses should be competent in discharge planning, it is evident that this is not necessarily translated into practice with anecdotal evidence locally suggesting there is a lack of understanding around responsibility for discharge planning.

The research that most informs this issue is that undertaken in the last ten years following the many changes implemented in the National Health Service (NHS) in England including the expansion of nursing roles with the introduction of many nurse led services including nurse-led discharge ${ }^{[2,7]}$. Most research has focused on nurses' perceptions of the discharge planning process and has highlighted several key problems that hinder effective and efficient discharge planning. These included nurses reporting a lack of involvement in the discharge planning process, and communication problems with discharge planning information not being prepared until the day of discharge or post-discharge ${ }^{[8-10]}$. Further problems were identified in a case study involving staff from three acute settings from a hospital in England whereupon different levels of staff expertise and communication difficulties, often exacerbated by the timing of nursing handovers, had a negative influence on the discharge process ${ }^{[11]}$. Problems around communication were also noted in a study that failed to persuade medical teams to enter the estimated date of discharge into diabetic patients' notes due to their reluctance and scepticism around the perceived benefits to the patients ${ }^{[12]}$. Similarly, in a study aimed at standardising patient board information to include estimated date of discharge it was reported that only $50 \%$ of staff were prepared to include this information ${ }^{[13]}$. Perhaps unsurprisingly the barriers to effective discharge planning were reported to include competing pressures, too much paperwork and the fact that staff often learnt about discharge planning informally ${ }^{[14]}$.

Several studies have explored the perceptions of nurses around discharge planning in more depth. In a survey of 58 nurses working in an intensive care unit, $43 \%$ believed they had a lack of understanding of the discharge planning process, and only $14 \%$ thought that the doctors provided enough direction for nurses to plan discharge ${ }^{[15]}$. In terms of when the discharge planning process should be commenced, $46 \%$ believed the process should start on admission to the intensive care unit, and 54\% just prior to the patient leaving the unit. The introduction of a discharge liaison nurse reported in a follow up study showed improved findings where only 15\% (compared with 43\%) felt they lacked understanding of the discharge planning process and 23\% (compared with 14\%) thought doctors provided sufficient direction to plan discharge. There was an increase from $34 \%$ to $68 \%$ who believed that discharge planning was the responsibility of the bedside nurse but little change in beliefs about when the discharge planning process should be commenced ${ }^{[16]}$. In a qualitative study of 12 registered nurses who worked in general medical/surgical wards, the majority believed that nurses had total control of the discharge planning process, and that the process was continuous from time of admission to discharge. However, in practice, the majority noted the discharge planning started at any point from admission to the date of discharge ${ }^{[17]}$. It was interesting to note from this study that some participants viewed discharge planning as requiring separate input from everyday care, and that discharge planning was viewed as a lower priority. Poor communication between medical and nursing staff in particular was viewed as a particular barrier to effective discharge planning. Although a different setting and different methodology employed, these results are consistent with those reported earlier. In a survey of 218 critical care nurses, $22 \%$ of the nurses felt that discharge planning did not take place in critical care; and of the remaining 170 , $51 \%$ believed that discharge planning was coordinated by a combination of health care professionals (mainly doctors and nurses), 33\% thought it was a nursing (primary or bedside nurse) responsibility and $14 \%$ a nurse manager responsibility. 
For those nurses working in units where primary nursing was used, 52\% stated that the bedside nurse/primary nurse coordinated the discharge planning process, compared with $29 \%$ of the nurses where patient allocation was organized by shift pattern ${ }^{[18,19]}$.

An interesting and important perspective on the communication between medical staff and nursing staff regarding the discharge planning process for patients in a high dependency unit was reported in an ethnographic study ${ }^{[20]}$. The findings revealed that the nurses often lacked assertiveness when discussing discharge planning with the medical team and were unable to present their case clearly when challenged. When there was pressure on beds, however, nurses were more able to make the case for discharge highlighting the need to develop skills around decision making and assertiveness. How different teams worked together on medical wards was the focus of a grounded theory study and as well as confirming the issues identified by others, the findings in this study also highlighted the observation that patients were never involved in the discussions around discharge planning ${ }^{[21]}$. Lack of patient involvement in the discharge planning process has been

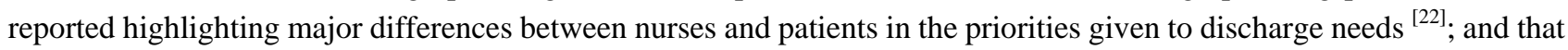
patients are not always given information regarding their likely date of discharge ${ }^{[23]}$. It is clear, however, that relatively simple initiatives can make major impacts on the discharge planning process. For example, the use of an A4 laminated card placed on bedside lockers known as the 'ticket home' resulted in a 19\% decrease (from 6.2 to 5 days) in the average length of stay for total hip replacement patients; and an increase in the numbers of patients discharged before midday and over the weekend (no figures provided). Additionally, at the start of the project $56 \%$ of patients achieved the predicted discharge date which rose to $86 \%$ three months later ${ }^{[24]}$.

Taken together and noting the differences in methodology and sample sizes, it can be seen from the findings reported here that there is a lack of coherence and consistency in how nurses working in a variety of settings perceive the discharge planning process. Poor communication between health care professionals and settings was noted as was a relative lack of involvement of nurses in the discharge planning process. Social problems were often not considered with an over-emphasis on ensuring patients were medically fit for discharge; and patient involvement in the discharge planning process was limited. Competing pressures were reported and it was clear from some findings that discharge planning was seen as a separate activity and not integral to care planning highlighting the importance of structured education and training around discharge planning. The benefits of ensuring good communication around care and discharge planning were reflected in reduced lengths of stay that emphasized the importance of getting this process implemented efficiently and effectively ${ }^{[24]}$.

Noting the problems reported locally which were consistent with the findings from the research reviewed, the aim of this study was to obtain more information about how the discharge planning process was perceived by registered nurses. The specific objectives were to identify views of nurses about their perceptions of the role and sills required by nurses in discharge planning; and to identify perceived barriers in implementing effective discharge planning.

\section{Subjects and methods}

\subsection{Design}

A cross-sectional survey of registered nurses on permanent contracts who worked in an acute hospital in the southwest of England

\subsection{Data collection}

Data were collected using a modified version of the discharge planning questionnaire developed by Chaboyer et al. for use with intensive care unit (ICU) nurses for which content validity was determined ${ }^{[15]}$. There was no information published about reliability. The questionnaire was modified by changing the wording of the questions to reflect the target population of registered nurses working across all clinical specialties. Content validity was rechecked by nurse academics with 
practice links familiar with the discharge planning process. The questionnaire contained Likert style statements with five response categories (strongly disagree, disagree, unsure, agree, strongly agree) or questions covering the following issues: 14 statements around perceptions of the discharge planning process (see Table 2 results for statements); seven statements about the timing of discharge planning (see Table 3); 16 statements about who normally or who should co-ordinate discharge planning; and 10 statements about perceived self-efficacy around discharge planning using the Schwarzer and Jerusalem scale used by Chaboyer ${ }^{[15]}$ et al. http://userpage.fu-berlin.de/ health/engscal.htm [accessed 4 November 2011]. In addition four open-ended questions were included to examine perceptions of the role and skills of nurses, and perceived barriers to effective discharge planning; and nine questions relating to personal characteristics and/or the place of work.

\subsection{Sample}

The sample consisted of 461 registered nurses employed by the hospital who worked full-time or part-time in areas in the acute hospital responsible for adult patients who would normally be discharged home rather than to another ward or unit. This information was provided by the divisional workforce team at the hospital headquarters using their database accurate as of February 2010. A letter of invitation outlining the details of the study together with a copy of the questionnaire was mailed to all nurses on the sampling frame in May 2010 with a follow-up questionnaire six weeks later to non-responders based on updated information from the divisional workforce team. The only information available for non-responders was name and place of work. Consent was presumed by the return of the questionnaire, with non-response following the second mailing taken as refusal to take part.

\subsection{Data analysis}

The data from the questionnaires was entered into SPSS 16.0 using single data entry. Standard statistical methods for questionnaire data were employed, including frequencies and percentages for each question, together with cross-tabulations for comparing opinions between different subgroups where the sample was large enough. The 10 self-efficacy questions were scored by summing the responses to all 10 items to result in a final scale score with a range from 10-40 [http://userpage.fu-berlin.de/ health/engscal.htm].

Thematic analysis was used to analyze the data from the four open-ended questions as follows. Two researchers each coded and then checked the codes for two questions using a sample of 14 questionnaires for each pair of questions. The research team then met to discuss the codes for all four questions and to explore any overarching themes. The themes and codes identified were then further checked and refined following analysis of a further 70 questionnaires.

\subsection{Ethics}

Ethical committee permission was granted from the relevant NHS research ethics committee (REC reference number 10/H0203/3) and the hospital Research and Development department.

\section{Results}

\subsection{Response rate}

Of the 461 questionnaires mailed, 137 were completed and returned (30\%). Similar surveys in this area yielded response rates between $43 \%{ }^{[18]}$ and $87 \%{ }^{[15]}$ although these studies targeted nurses working in specific areas and the latter used a sample of 65 nurses from one ICU. The characteristics of those responding are shown in Table 1 from which it can be seen that the respondents were predominantly female, working full-time and as staff nurses. The majority of the respondents were working in acute medicine, although there was reasonable representation from those working in surgical areas. The average number of discharges was 12 per week (median 6) with an extremely wide range of 0 to 99 . In $70 \%$ of cases, ward rounds were undertaken once a day. 
Table 1. Characteristics of Respondents

\begin{tabular}{|c|c|c|}
\hline Scale & Frequency (\%) & Mean (SD) \\
\hline Female & $124(91)$ & \multirow[b]{2}{*}{ na } \\
\hline Male & $12(9)$ & \\
\hline Age (years) & na & $43(10.5)$ \\
\hline Years Worked as Registered Nurse (range $<1$ to 41 ) & na & $16(11)$ \\
\hline Enrolled Nurse & $4(3)$ & \multirow{7}{*}{ na } \\
\hline Staff Nurse & $94(69)$ & \\
\hline Senior Staff Nurse & $17(12)$ & \\
\hline Matron & $4(3)$ & \\
\hline Senior Matron & $1(1)$ & \\
\hline Unit Manager & $11(8)$ & \\
\hline Other & $5(4)$ & \\
\hline Years Working in Current Post (range $<1$ to 23 ) & na & $7(5)$ \\
\hline Full-time & $86(63)$ & \multirow[b]{2}{*}{ na } \\
\hline Part-time & 50 (37) & \\
\hline Acute medicine & $42(31)$ & \multirow{11}{*}{ na } \\
\hline Specialty medicine & $6(4)$ & \\
\hline Cancer services & $4(3)$ & \\
\hline Cardiology & $8(6)$ & \\
\hline Eldercare & $11(8)$ & \\
\hline General surgery & $15(11)$ & \\
\hline Specialist surgery & $3(2)$ & \\
\hline Trauma and orthopaedics & $24(17)$ & \\
\hline Head and neck & $5(4)$ & \\
\hline Obstetrics and gynaecology & $5(4)$ & \\
\hline Other & $11(8)$ & \\
\hline Average number of discharges initiated per week (range 0-99) & na & $12(16.5)$ \\
\hline \multicolumn{3}{|c|}{ Frequency of ward rounds/patient reviews conducted in unit for patients normally under the care of one consultant } \\
\hline Twice daily & $22(17)$ & \multirow{3}{*}{ na } \\
\hline Once a day & $91(70)$ & \\
\hline Other (e.g. twice weekly $n=6$, no rounds $n=3$, when required $n=4$ ) & $17(13)$ & \\
\hline
\end{tabular}

\subsection{Respondents' perceptions of the discharge planning process}

The results presented in Tables 2 and 3 illustrate the respondents' perceptions of the discharge planning process in their unit and how they think discharge planning should be organized. Quotation marks are used to reflect the wording of the statements in the questionnaire. From Table 2 it can be seen that approximately $76 \%$ of respondents believed that 'discharge planning is the responsibility of the bedside nurse', although this figure decreased to $59 \%$ who agreed that 'discharge planning should be the responsibility of the bedside nurse'. With regard to the 34 of the latter who disagreed 
that discharge planning should be the responsibility of the nurse, 11 worked in acute medicine, which represents $26 \%$ of those who participated from acute medicine; 7 in trauma and orthopaedics (29\% of respondents from this area), and 3 in eldercare (27\% of respondents from this area). Of the 63 who disagreed with the statement that 'doctors provide enough direction for nurses to plan discharges' 16 worked in acute medicine (38\% of the sample), 9 in both general surgery (60\% of the sample who worked in this area) and trauma and orthopaedics (37.5\% of the sample), and 6 in eldercare (54.5\% of the sample).

Table 2: Perceptions around The Discharge Planning Process in the Respondents’ Unit (\% in parentheses)

\begin{tabular}{|c|c|c|c|}
\hline Statement $(\mathrm{D} / \mathrm{CP}=$ discharge planning $)$ & $\begin{array}{l}\text { Strongly } \\
\text { Disagree/ } \\
\text { Disagree }\end{array}$ & Unsure & $\begin{array}{l}\text { Strongly } \\
\text { Agree/ } \\
\text { Agree }\end{array}$ \\
\hline $\mathrm{D} / \mathrm{CP}$ is the responsibility of the bedside nurse & $25(18.3)$ & $8(5.8)$ & $104(75.9)$ \\
\hline Doctors provide enough direction for nurses to plan D/C & $63(44.6)$ & $25(18)$ & $47(34)$ \\
\hline Nurses in general have a lack of understanding of the $\mathrm{D} / \mathrm{C}$ process & $90(66.2)$ & $17(12)$ & $29(21.3)$ \\
\hline Patients are fully involved in the $\mathrm{D} / \mathrm{CP}$ process & $33(24.6)$ & $22(16.4)$ & $79(59)$ \\
\hline $\mathrm{D} / \mathrm{CP}$ is useful & $2(1.5)$ & $2(1.5)$ & $133(97)$ \\
\hline $\mathrm{D} / \mathrm{CP}$ is time consuming & $21(15.4)$ & $6(4.4)$ & $109(80.1)$ \\
\hline $\mathrm{D} / \mathrm{CP}$ means more paperwork & $24(17.2)$ & $8(5.8)$ & $105(76.6)$ \\
\hline $\mathrm{D} / \mathrm{CP}$ is beneficial for the patients & $3(2.2)$ & - & $134(97.8)$ \\
\hline $\mathrm{D} / \mathrm{CP}$ is difficult when patient recovery is not certain & $8(5.8)$ & $6(4.4)$ & $123(89.8)$ \\
\hline $\mathrm{D} / \mathrm{CP}$ is not a priority & $105(77.2)$ & $12(8.8)$ & $19(14.0)$ \\
\hline $\mathrm{D} / \mathrm{CP}$ should be the responsibility of the bedside nurse & $34(25.6)$ & $20(15)$ & $79(59.4)$ \\
\hline Patients are normally discharged before midday & $113(82.4)$ & $11(8)$ & $13(9.5)$ \\
\hline $\begin{array}{l}\text { Patients are normally discharged to a 'discharge lounge' or something } \\
\text { similar }\end{array}$ & $84(62.2)$ & $9(6.7)$ & $42(31.1)$ \\
\hline Patients may be discharged on any day during the week & $16(11.7)$ & $4(2.9)$ & $117(85.4)$ \\
\hline
\end{tabular}

Approximately $25 \%$ of respondents $(n=33)$ disagreed with the statement that 'patients are fully involved in the discharge planning process'; 12 out of the 33 worked in acute medicine (29\% of respondents from this area); 5 in trauma and orthopaedics (representing $21 \%$ of respondents from this area), and 5 in eldercare (45\% of respondents from this area). Over $60 \%$ of respondents disagreed that 'patients are normally discharged to a discharge lounge or something similar', with 25 working in acute medicine (59.5\% of respondents from this area), 19 in trauma and orthopaedics (79\% of respondents), and 8 in eldercare $73 \%$ of respondents).

Four themes were identified from the responses to the open-ended question 'what do you consider the discharge planning process to involve? These were: (i) having a good overview ( $\mathrm{n}=78$ ) which included having a holistic approach, being patient centred, and involving family and friends; (ii) safety ( $\mathrm{n}=59)$ which included ensuring appropriate timing, providing a safe discharge package, ensuring a support network was in place, and that activities of daily living were met; (iii) co-ordination ( $\mathrm{n}=85$ ) that involved general co-ordination, involving the MDT, liaising with the care coordinator, and ensuring a social package was in place; and (iv) planning $(n=36)$ which included starting the discharge process on admission, and assessing whether it was a simple or complex discharge. 


\subsection{Perceptions of the timing and implementation of discharge planning}

The information presented in Table 3 shows that nearly $80 \%$ of respondents believed that 'discharge planning should be commenced on admission to the unit'; and 76.5\% believed that an 'estimated date of discharge is provided for each patient'. However, nearly 50\% disagreed with the statement that 'the estimated date for discharge is always communicated to the patient' and 38\% of this group of 63 were based in acute medicine. It was noteworthy that only $10 \%$ believed that 'patients are normally discharged before midday'.

Table 3. Perceptions around the Timing and Implementation of Discharge Planning in the Respondents' Unit (\% in parentheses)

\begin{tabular}{|c|c|c|c|}
\hline Statement $(\mathrm{D} / \mathrm{CP}=$ discharge planning $)$ & $\begin{array}{l}\text { Strongly } \\
\text { Disagree/ } \\
\text { Disagree }\end{array}$ & Unsure & $\begin{array}{l}\text { Strongly Agree/ } \\
\text { Agree }\end{array}$ \\
\hline $\mathrm{D} / \mathrm{CP}$ should be commenced on admission to the unit & $17(12.2)$ & $11(8)$ & 109 (79.5) \\
\hline $\mathrm{D} / \mathrm{CP}$ should be commenced just prior to the patient leaving the unit & $129(94.1)$ & $3(2.2)$ & $5(3.6)$ \\
\hline $\mathrm{D} / \mathrm{CP}$ should be commenced when the family requests it & $104(76.5)$ & $12(8.8)$ & $20(14.7)$ \\
\hline $\mathrm{D} / \mathrm{CP}$ should be commenced when the doctor requests it & $73(53.3)$ & $14(10.2)$ & $50(36.5)$ \\
\hline $\mathrm{D} / \mathrm{CP}$ should be commenced when other health professionals request it & $63(46)$ & $22(16.1)$ & $52(37.9)$ \\
\hline An estimated date for discharge is provided for each patient & $22(16.1)$ & $10(7.4)$ & $104(76.5)$ \\
\hline $\begin{array}{l}\text { The estimated date for discharge is always communicated to the } \\
\text { patient }\end{array}$ & $63(45.9)$ & $23(16.8)$ & $51(37.2)$ \\
\hline
\end{tabular}

Consistent with the data reported in Table 2, the majority of respondents did not believe that discharge planning should commence when the family or doctor requests it. In $76 \%$ of cases there was agreement that 'a discharge plan is normally coordinated by the patient's allocated nurse', and nearly $80 \%$ agreed that 'a discharge plan should be coordinated by the patient's allocated nurse'. Eighty-six per cent agreed that 'a discharge plan is normally coordinated by the multidisciplinary team (MDT)'; with 90\% agreeing that 'a discharge plan should be undertaken by the MDT'. This compares with the less than $50 \%$ who agreed that 'a discharge plan is normally', or 'should be coordinated by the nurse in charge of the unit for that shift'. Thirty-five per cent of respondents agreed that 'a discharge plan is normally coordinated by the hospital discharge planning team', but $62 \%$ of respondents agreed that 'a discharge plan should be coordinated by the hospital discharge planning team'.

\subsection{Role and skills of nurses in discharge planning}

Three main themes were identified from the open-ended question 'what do you think should be the role of nurses in the discharge planning process': liaison/referral ( $n=99)$; assessment $(n=50)$, and patient advocacy ( $n=17)$. When asked 'what specific skills do you think are needed by nurses to carry out discharge planning?' the data were grouped into two key themes: management and personal skills $(n=95)$; and discharge planning management $(n=75)$. The first theme related to skills such as problem-solving, good communication skills, time management skills and good organizational skills; and the second theme included being able to understand the clinical assessment process, having effective documentation knowledge and skills, being knowledgeable about services, resources and referral systems; and being able to plan safe discharges, and challenge unnecessary discharges.

With regard to the respondents' measure of perceived self-efficacy in relation to discharge planning, the results showed a mean scale score of 29.8 (s.d. 3.6) and a range from 22 to 40, which suggested a moderate degree of self-efficacy in the context of discharge planning. 


\subsection{Barriers to conducting effective discharge planning}

The main themes identified from the responses to the question 'what do you think are the barriers to conducting effective discharge planning in your unit?’ were: (i) internal discharge planning systems ( $\mathrm{n}=66)$ such as poor or no planning, limited access to diagnostic facilities etc., lack of documentation, delayed medical review, patients not meeting the estimated discharge date, and poor assessment on admission; (ii) external discharge planning systems ( $\mathrm{n}=33$ ) which included bed blocking, and lack of input from external services such as social services and psychiatric services; and (iii) management/personal skills ( $\mathrm{n}=73$ ) such as time issues, poor staffing levels, confidence, and poor communication.

\section{Discussion}

The main rationale for this survey was the recognition that discharge planning was not being implemented as planned in an acute hospital. Several government papers published in recent years that focused on the provision of care noted problems around discharge planning suggesting that not all registered nurses were engaged in the discharge planning process as expected. These national contextual factors together with anecdotal difficulties reported locally resulted in the design of this survey; the aim of which was to explore the perceptions that nurses held towards the discharge planning process in an acute hospital with a focus on attitudes to key elements of discharge planning, views around the roles and skills required by nurses in discharge planning; and identifying barriers that hindered effective discharge planning. The fundamental purpose being to collect data that could be used to inform decision making about policy and documentation changes needed to improve the discharge planning process.

\subsection{Respondents' perceptions of the discharge planning process}

The main findings showed that those who responded believed the bedside, or patient's allocated nurse, was primarily responsible for discharge planning, and that the process was beneficial to patients, and clearly of priority. The majority, however, believed that the process should be coordinated by the discharge planning liaison team suggesting a view that discharge planning should be the responsibility of an alternative, rather than ward based team. It is clear from the results that some nurses had a lack of understanding about the discharge planning process, also reported in the Chaboyer et al. study ${ }^{[15]}$. It is important for the success of discharge planning to have systems and processes in place and that the health care professionals understand who is responsible at each stage of those systems and processes. Otherwise there is confusion amongst who should be doing what and gaps appear in the provision of the service.

Only one-third believed that doctors provided enough direction for nurses to plan the discharge process. Furthermore, it was clear that patients were not wholly involved in the planning around their discharge which is consistent with that reported in a qualitative study in which only two out of ten patients reported being given information about the likely date

of discharge ${ }^{[23]}$. Taken together, these findings suggest communication difficulties between key health care professionals and a lack of understanding around the discharge planning process. Good communication creates strong, productive relationships across and between individuals and agencies; whilst a commitment to coordination will contribute towards seamless services that foster the dovetailing of processes. There is a need for greater co-operation between the many healthcare professions involved; the adoption, particularly on the part of nursing staff, of a more holistic approach with regard to the needs of their patients will also enhance the utilization of nursing staff. The role of the nurse in liaising with patients, patients' families and their own professional colleagues is central to achieving the smooth transition of care across service interfaces, fundamental in ensuring a successful discharge planning process.

\subsection{Perceptions of the timing and implementation of discharge planning}

It could be argued that tighter processes around discharge planning and a policy on discharging over a full week would enable more morning and weekends discharges, which in turn would help increase bed availability. Admission patterns often follow the day of the week as do discharges, with a rush to discharge patients on a Friday to clear beds for the weekends. Few discharges actually take place over the weekend which can cause problems especially on a Monday when 
there may be many admissions for inpatient elective care. In terms of planning discharges and communicating this information to patients, it is important to remember that most patients want to know how long they are likely to stay in hospital, want information about their treatment and when they are likely to be discharged in order to ensure they are fully engaged with the treatment planning process and therefore able to plan effectively for any arrangements they need to make in readiness for their discharge.

It should be noted that the hospital published their guideline on "Transfer and Discharge of Adult Inpatient Areas" in June 2009 and identified key points for implementation. This guidance was implemented seven months prior to the first mailing of questionnaires and, therefore, it could be argued that it should have been more evident from the results that this was being routinely utilised in clinical practice. As indicated above in relation to patient communication, it is clear that some fundamental principles of the process were failing including the aim to discharge most patients before midday. Furthermore, in March 2010, the Department of Health in England published a resource to aid discharge planning which contained 10 key steps to help hospitals plan patients' discharge which further reinforces the local guidance and should reassure staff that there is robust guidance around the discharge planning process ${ }^{[25]}$.

\subsection{Barriers to conducting effective discharge planning}

Whilst all practitioners will readily agree with the principles of good discharge planning, it is recognized that individual patient needs have become more complex which has an impact on discharge planning as reflected by the finding that $90 \%$ of respondents felt that it was difficult to plan a discharge when the recovery of the patient was uncertain. At the same time, pressure on beds and other resources has increased dramatically and this factor coupled with poor communication results in unnecessary pressures on staff who cannot then execute discharge planning effectively. The sense of frustration many nurses felt in the context of discharge planning was reflected in the themes that emerged from the open-ended questions. This revealed many perceived barriers that hindered discharge planning. These centred in the main around poor planning and communication problems with both internal and external teams; the latter particularly around problems with access to social services out of hours and at weekends as well as other professional teams such as occupational therapists. Delayed medical review and poor staffing levels were also highlighted by many as well as issues around time.

Although information was collected about the frequency of ward rounds, questions were not included about whether daily discussions took place around discharge planning. A large teaching hospital in East Anglia in England expects staff to engage in short, daily meetings to discuss each patient's discharge plan with a focus on four key questions: Why is the patient still in hospital? When will the patient be able to leave hospital? Will the patient need ongoing support on discharge? Is the patient aware of the discharge plan? Brief documents that highlight key elements of the discharge process and the major benefits are also posted on the hospital intranet (Stafford-Sheath, 2010, personal communication). Information is also provided for patients that emphasise their involvement in discharge planning http://www.cuh.org.uk/ addenbrookes/patients/inpatients/planning_discharge.html [accessed 20 October 2010] and this is further reinforced in a clearly presented A5 leaflet provided to all patients upon admission.

Increased visibility of a patient's discharge plan can help to avoid misunderstandings with the patient and family regarding the discharge pathway and ensure the plan is implemented efficiently and effectively which will in turn lead to improved patient care and ultimately patient satisfaction. It is evident from the results that some respondents felt overwhelmed and/or perceived a pressure to discharge patients in a timely manner. Such pressure could have an adverse effect and add unnecessary stress to staff already working in a difficult work environment with reduced staff levels and at a time of great change. This is also at a time when hospitals nationally are trying to implement health and wellbeing policies in support of their staff ${ }^{[26]}$.

The findings from this survey have to be placed in the context of the relatively low response rate. It was unfortunate that the survey took place in the year in which the hospital underwent two major restructurings around nursing organization; and rebuilding works which necessitated the staff at one of the units being relocated. It has to be considered therefore that 
the responses from the staff who participated in this survey might be unrepresentative of the wider population of staff. We did however have reasonable representation from both medical and surgical areas and believe that the findings will be of value to those looking at how best to improve the process around discharge planning. Additionally, the fact that the results were consistent with the findings from others confirms that the complexities of discharge planning are not unique to this one hospital ${ }^{[6,8,15]}$; and that systems and processes need to be not only in place but embedded into routine practice. Discharge planning needs to be high on the agenda within any hospital for that to take place.

\section{Acknowledgement}

We would like to thank Alex Watt, Research Assistant, for preparing the questionnaires for mailing, entering the data on to SPSS and coding the qualitative data.

\section{Sources of support}

Royal Cornwall Hospitals Trust

\section{Conflicting interest}

None

\section{References}

[1] Department of Health. Achieving timely 'simple' discharge from hospital. A toolkit for the multi-disciplinary team. London: Department of Health. 2004.

[2] Department of Health. Discharge from hospital: pathway, process and practice. London: Department of Health. 2003.

[3] Shepperd S, Parkes J, McClaran J, \& Phillips C. Discharge planning from hospital to home. London: John Wiley \& Sons, Ltd., L ondon. 2004.

[4] Shepperd S, McClaran J, Phillips C, Lannin N, Clemson L, McCluskey A. et al. Discharge planning from hospital to home. Cochrane Database of Systematic Reviews. 2010. http://dx.doi.org/10.1002/14651858.CD000313.pub3

[5] Healthcare Commission. Spotlight on Complaints. A Report on Second-Stage Complaints about the NHS in England. London: Healthcare Commission. 2007.

[6] Goodman H. Discharge from hospital: the importance of planning. British Journal of Cardiac Nursing. 2010 ; 5: $274-279$.

[7] Brook, N. Nurse-led discharge planning improves quality of care. Nursing Times. 2001; 97: 40.

[8] McKenna H, Keeney S, Glenn A, Gordon P. Discharge planning: an exploratory study. Journal of Clinical Nursing, 2000; 9: 594-601. PMid:11261142 http://dx.doi.org/10.1046/j.1365-2702.2000.00384.x

[9] Dunnion M, Kelly B. From the emergency department to home. Journal of Clinical Nursing. 2005; 14: 776-785. PMid:15946286 http://dx.doi.org/10.1111/j.1365-2702.2005.01129.x

[10] Dunnion M, Kelly B. Discharge of the older person from the emergency department - the perceptions of health professionals. International Journal of Older People Nursing. 2007; 2: 102-110. PMid:20925786 http://dx.doi.org/10.1111/j.1748-3743.2007.00068.x

[11] Atwal A. Nurses' perceptions of discharge planning in acute health care: a case study in one British teaching hospital. Journal of Advanced Nursing. 2002; 39: 450-458. PMid:12175354 http://dx.doi.org/10.1046/j.1365-2648.2002.02310.x

[12] Lees L, Holmes C. Estimating date of discharge at ward level: a pilot study. Nursing Standard. 2005; 19: 40-43.

[13] Lees L, Delpino, R. Facilitating an effective discharge from hospital. Nursing Times. 2007; 103: 30-31.

[14] Connolly M, Grimshaw J, Dodd M, Cawthorne J, Hulme T, Everitt S, et al. Systems and people under pressure: the discharge process in an acute hospital. Journal of Clinical Nursing. 2009; 18: 549-558. PMid:19192004 http://dx.doi.org/10.1111/j.1365-2702.2008.02551.x

[15] Chaboyer W, Foster M, Kendall E, James H. ICU nurses' perceptions of discharge planning: a preliminary study. Intensive and Critical Care Nursing. 2002; 18: 90-95. http://dx.doi.org/10.1016/S0964-3397(02)00022-8

[16] Chaboyer W, Foster M, Kendall E, James H. The impact of a liaison nurse on ICU nurses' perceptions of discharge planning. Australian Critical Care. 2004; 17: 25-32. http://dx.doi.org/10.1016/S1036-7314(05)80047-5

[17] Watts R, Gardner H. Nurses' perceptions of discharge planning. Nursing and Health Sciences. 2005; 7: 175-183. PMid:16083480 http://dx.doi.org/10.1111/j.1442-2018.2005.00229.x 
[18] Watts R, Pierson J, Gardner H. How do critical care nurses define the discharge planning process? Intensive and Critical Care Nursing. 2005; 21: 39-46. PMid:15681216 http://dx.doi.org/10.1016/j.iccn.2004.07.006

[19] Watts R, Pierson J, Gardner H. Co-ordination of the discharge planning process in critical care. Journal of Clinical Nursing. 2006; 16: 202.

[20] Brand S. Nurses' roles in discharge decision making in an adult high dependency unit. Intensive and Critical Care Nursing. 2006; 22: 106-114. PMid:16198571 http://dx.doi.org/10.1016/j.iccn.2005.04.003

[21] Pethybridge J. How team working influences discharge planning from hospital: a study of four multi-disciplinary teams in an acute hospital in England. Journal of Interprofessional Care. 2004; 18: 29-41. PMid:14668100 http://dx.doi.org/10.1080/13561820410001639334

[22] Anthony M., Hudson-Barr D. A patient-centered model of care for hospital discharge. Clinical Nursing Research. 2004; 13: 117-138. PMid:15104855 http://dx.doi.org/10.1177/1054773804263165

[23] Lees L. Estimating patient discharge dates. Nursing Management. 2008; 15: 30-35.

[24] Webber-Maybank M., Luton H. Making effective use of predicted discharge dates to reduce the length of stay in hospital. Nursing Times.net. 2009; 21: 1-5.

[25] Department of Health. Ready to go? Planning the discharge and the transfer of patients from hospital and intermediate care, London: Department of Health, London. 2010.

[26] Department of Health. NHS Health and Well-being Final Report, Department of Health, London. 2009. 